\title{
Strategi Guru dalam Menerapkan Pembelajaran Aktif Inovatif Kreatif Efektif dan Menyenangkan (PAIKEM) pada Pembelajaran Pendidikan Agama Islam di SDN X Astanaanyar Kota Bandung
}

\author{
Rifa Nur Fauziyah* \\ Prodi Pendidikan Agama Islam, Fakultas Tarbiyah dan Keguruan, \\ Universitas Islam Bandung, Indonesia. \\ *rifanurfauziyah1@gmail.com
}

\begin{abstract}
In learning Islamic Religious Education teachers still use methods that are less varied. The use of this method makes students feel bored and less enthusiastic in learning so that their learning progress does not go well. Teachers are required to be proficient in designing learning, implementing and conducting assessments. In designing learning the teacher chooses a variety of methods and optimal methods, so that students can receive information and knowledge well, for example by using the PAIKEM model. So it is necessary to conduct research on teacher strategy analysis in implementing active, innovative, creative and effective learning. The purpose of this study is to describe (1) learning planning using the PAIKEM model in Islamic Religious Education subjects (2) the implementation of learning using the PAIKEM model in Islamic Religious Education subjects (3) learning evaluation using the PAIKEM model in Islamic Religious Education subjects. This study uses a qualitative approach with qualitative descriptive methods, the type of case study conducted at SDN X Astanaanyar Bandung City. Data collection techniques are interviews, observation and documentation. With data analysis techniques using data reduction steps, data presentation and conclusions. The results of the study can be found that the learning planning carried out by Islamic Religious Education teachers is in accordance with the characteristics of PAIKEM. In the implementation of learning, Islamic Religious Education teachers still use the lecture method and the question and answer method, but are accompanied by several methods that make students learn actively, innovatively and effectively, namely the True or False method, Role Play, Reading Aloud and Random Text. In the evaluation of learning, the Islamic Religious Education teacher first makes an evaluation plan, namely making exam grids and making questions with HOTS (Higher Order Thinking Skills) questions indicators.
\end{abstract}

Keywords: Teacher, PAIKEM Strategy, Islamic Religious Education

\begin{abstract}
Abstrak. Dalam pembelajaran Pendidikan Agama Islam guru masih menggunakan metode yang kurang bervariasi. Penggunaan metode tersebut yang membuat siswa merasa jenuh dan kurang bersemangat dalam belajar sehingga kemajuan belajarnya tidak berjalan dengan baik. Guru dituntut mahir dalam merancang pembelajaran, melaksanakan dan melakukan penilaian. Dalam merancang pembelajaran guru memilih metode yang bervariasi dan metode yang optimal, agar siswa dapat menerima informasi dan pengetahuan dengan baik, misalnya dengan menggunakan model PAIKEM. Maka perlu dilakukan penelitian analisis strategi guru dalam menerapkan pembelajaran aktif, inovatif, kreatif dan efektif. Tujuan dari penelitian ini yaitu mendeskripsikan (1) perencanaan pembelajaran menggunakan model PAIKEM pada mata pelajaran Pendidikan Agama Islam (2) pelaksanaan pembelajaran menggunakan model PAIKEM pada mata pelajaran Pendidikan Agama Islam (3) evaluasi pembelajaran menggunakan model PAIKEM pada mata pelajaran Pendidikan Agama Islam. Penelitian ini menggunakan pendekatan kualitatif dengan metode deskriptif kualitatif, tipe studi kasus yang dilakukan di SDN X Astanaanyar Kota Bandung. Teknik pengumpulan data yaitu wawancara, observasi dan dokumentasi. Dengan teknik analisis data menggunakan langkah reduksi data, penyajian data dan kesimpulan.Hasil penelitian dapat ditemukan bahwa perencanaan pembelajaran yang dilakukan oleh guru Pendidikan Agama Islam sesuai dengan karakteristik PAIKEM. Dalam pelaksanaan pembelajaran guru Pendidikan Agama Islam masih menggunakan metode ceramah dan metode tanya jawab, namun disertai beberapa metode yang membuat siswa belajar secara aktif, inovatif dan efektif yakni metode True or False, Role Play, Reading Aloud dan Teks Acak. Pada evaluasi pembelajaran guru Pendidikan Agama Islam terlebih dahulu membuat perencanaan evaluasi yaitu membuat kisi-kisi ujian dan membuat soal dengan indikator soal HOTS (Higher Order Thinking Skills).
\end{abstract}

Kata Kunci: Guru, Strategi PAIKEM, Pendidikan Agama Islam 


\section{A. Pendahuluan}

Pendidikan merupakan komponen utama dalam kehidupan manusia. Melalui pendidikan, manusia dapat lebih mengembangkan pengetahuan dan kemampuan, meningkatkan kualitas kehidupan, dan dapat mengenal dirinya sendiri. Dijelaskan pula dalam Undang-undang No.20 tahun 2003 bahwa, pendidikan secara umum merupakan usaha sadar dan terencana untuk mewujudkan suasana belajar dan proses pembelajaran agar peserta didik secara aktif mengembangkan potensi dirinya untuk memiliki kekuatan spiritual keagamaan, pengendalian diri, kepribadian, kecerdasan, akhlak mulia serta keterampilan yang diperlukan dirinya, masyarakat, bangsa dan Negara.

Untuk dapat mencapai pengembangan potensi siswa dalam kekuatan spiritual keagamaan dan akhlak mulia, maka diperlukan mata pelajaran Pendidikan Agama Islam. Pendidikan Agama Islam merupakan studi tentang ajaran agama Islam. Pendidikan Agama Islam diuraikan dalam materi ajar. Pendidikan Agama Islam disampaikan dalam proses pembelajaran melalui bimbingan, latihan dibatasi dengan ruang lingkup kajian keislaman. Mata pelajaran Pendidikan Agama Islam diberikan kepada peserta didik di satuan pendidikan di setiap jenjang dan jenis pendidikan. Mata pelajaran pendidikan agama islam diharapkan mampu memandirikan peserta didik dan memberdayakannya di masyarakat (Asfiati, 2020: 52).

Tujuan Pendidikan Agama Islam di tingkat Sekolah Dasar yaitu menumbuhkan dan meningkatkan keimanan melalui pemberian dan pemupukan pengetahuan, penghayatan, pengamalan serta peserta didik tentang agama Islam sehingga menjadi manusia muslim yang terus berkembang dalam hal keimanan, ketakwaan kepada Allah SWT serta berakhlak mulia dalam kehidupan pribadi, bermasyarakat, berbangsa dan bernegara, serta untuk melanjutkan ke jenjang pendidikan yang lebih tinggi (Hamid, Hamdani, 2012: 239). Materi ajar dalam Pendidikan Agama Islam memiliki kaitan erat dengan rumusan tujuan Pendidikan Agama Islam. Untuk mencapai tujuan tersebut maka ruang lingkup materi ajar pada dasarnya mencakup tujuh unsur pokok, yaitu al-Qur' an- Hadits, keimanan, syariah, ibadah, muamalah, akhlak, dan tarikh (sejarah Islam).

Dalam materi pembelajaran Pendidikan Agama Islam dibutuhkan strategi pembelajaran dengan PAIKEM. Melihat fenomena yang terjadi selama ini adalah pada saat pembelajaran Pendidikan Agama Islam, siswa mengalami kejenuhan belajar, yang membuat kerangka berpikirnya tidak dapat menerima informasi atau pengetahuan yang telah dijelaskan, sehingga kemajuan belajarnya bagaimanapun juga tidak dapat berjalan dengan baik. Hal tersebut terjadi kurangnya penguasaan materi pelajaran yang disampaikan oleh guru dan penerapan metode pembelajaran yang kurang bervariasi (mononton).

PAIKEM atau singkatan dari pembelajaran, aktif, inovatif, efektif, kreatif dan menyenangkan ini merupakan model pembelajaran yang dapat memungkinkan peserta didik untuk mengembangkan berbagai keterampilan, sikap dan pemahaman melalui berbagai sumber dari media pembelajaran. PAIKEM bertujuan untuk meningkatkan pembelajaran untuk lebih menarik ,menyenangkan dan efektif serta membuat siswa nyaman ketika proses pembelajaran berlangsung. Selain siswa, sebenarnya guru juga dituntut untuk aktif dan kreatif, agar penerapan PAIKEM ini dapat berjalan dengan sesuai tujuan pembelajaran.

Alhamuddin and Bukhori Said: "The Teacher plays a central role as a facilitator of instruction. Learners are facilitated to proceed to master teaching materials prepared with a variety of instruction resources". This statement is supported by the results of a study conducted in 29 countries showing that among the various inputs determining the success of education (student achievement), more than a third are determined by the teacher. Guru sebagai tenaga pendidik harus mahir dalam merancang pembelajaran, melaksanakannya dan melakukan penilaian hasil (evaluasi) belajar.

Strategi PAIKEM merupakan strategi yang sangat relevan untuk digunakan dalam pembelajaran Pendidikan Agama Islam. Di Bandung terdapat Sekolah Dasar yang sudah menerapkan strategi PAIKEM dalam pembelajaran Pendidikan Agama Islam, maka dapat dikatakan strategi ini memberikan manfaat yang cukup besar dalam meningkatkan inovasi pembelajaran. Pembelajaran yang memusat pada keaktifan belajar siswa ini, mampu melahirkan pribadi-pribadi muslim yang memiliki akhlak al-karimah dan etos kerja yang tinggi pada diri 
siswa.

SDN X Astanaanyar selalu terbuka terhadap strategi atau metode baru untuk meningkatkan kegiatan pembelajaran yang lebih baik seperti strategi PAIKEM. Apabila guru dapat mengelola strategi PAIKEM ini dengan baik, maka akan tercapailah tujuan pembelajaran Pendidikan Agama Islam. Pada umumnya di beberapa Sekolah Dasar, sudah banyak menerapkan strategi PAIKEM, namun hasilnya belum maksimal.

Dilihat dari uraian latar belakang diatas, maka penulis merumuskan masalah sebagai berikut:

1. Bagaimana perencanaan pembelajaran dengan menggunakan model PAIKEM dalam mata pelajaran Pendidikan Agama Islam di SDN X Astanaanyar Kota Bandung?

2. Bagaimana pelaksanaan pembelajaran dengan menggunakan model PAIKEM dalam mata pelajaran Pendidikan Agama Islam di SDN X Astanaanyar Kota Bandung?

3. Bagaimana evaluasi pembelajaran dengan menggunakan model PAIKEM dalam mata pelajaran Pendidikan Agama Islam di SDN X Astanaanyar Kota Bandung?

\section{B. Metodologi Penelitian}

Peneliti menggunakan metode deskriptif kualitatif dengan jenis studi kasus, dengan menggunakan pendekatan kualitatif. Sumber data yang digunakan adalah sumber data primer yaitu Kepala Sekolah, Guru PAI dan Siswa SDN X Astanaanyar, serta sumber data sekunder berupa dokumen (RPP)

Dengan teknik pengumpulan data yaitu wawancara, observasi dan dokumentasi. Melakukan wawancara dengan Kepala Sekolah, Guru PAI dan Siswa SDN X Astanaanyar. Observasi dengan mengamati proses pembelajaran yang sedang berlangsung di kelas dengan menggunakan strategi PAIKEM. Adapun teknik analisis data yang digunakan dalam penelitian ini adalah reduksi data (meringkas atau merangkum), penyajian data (mendeskripsikan hasil penelitian berupa uraian singkat) dan menarik kesimpulan.

\section{Hasil Penelitian dan Pembahasan}

Perencanaan pembelajaran menggunakan model PAIKEM pada mata pelajaran Pendidikan Agama Islam di SDN X Astanaanyar

Guru PAI di SDN X Astanaanyar, sebelum melakukan proses pembelajaran, terlebih dahulu menyiapkan perencanaan pembelajaran secara optimal dengan menentukan tujuan pembelajaran, materi pembelajaran, metode yang bervariatif, langkah-langkah yang efektif dan efisien dan menggunakan sumber belajar yang beraneka ragam, tidak hanya melalui buku saja. Menurut (Remiswal \& Rezki Amelia: 2013: 66) dalam pembuatan perencanaan pembelajaran yang harus diperhatikan adalah sesuai dengan karakteristik PAIKEM yaitu adanya sumber yang beraneka ragam kemudian didesain menjadi berbagai kegiatan, hasil kegiatan belajar mengajar dipajang di dinding kelas, kegiatan belajar mengajar bevariasi secara aktif, dalam mengerjakan berbagai tugas siswa baik secara individu maupun secara berkelompok mencoba mengembangkankreativitasnya semaksimal mungkin, dan dalam melaksanakan kegiatan yang beraneka ragam tersebut nampak kesenangan atau antusias siswa.

Perencanaan pembelajaran harus tersusun secara sistematis dan optimal. Guru wajib membuat perencanaan sebelum mengajar, karena hal tersebut merupakan suatu kompetensi yang harus diwujudkan untuk tercapainya tujuan pembelajaran secara optimal. Sebagai suatu alat bantu tenaga pendidik dalam melaksanakan tugas dan fungsinya, perencanaan pembelajaran menjadi hal yang sangat penting dan sangat menentukan. Sebagaimana menurut E. Mulyasa, dkk (2016: 36) setiap melakukan pembelajaran guru wajib memiliki persiapan, baik persiapan tertulis maupun tidak tertulis. Dosa hukumnya bagi guru yang melaksanakan pembelajaran tanpa persiapan karena hal tersebut dapat merusak mental dan moral peserta didik.

\section{Pelaksanaan pembelajaran menggunakan model PAIKEM pada mata pelajaran Pendidikan Agama Islam di SDN X Astanaanyar}

Pada kegiatan awal, ketiga guru PAI melakukan hal yang sama, yaitu diawali dengan membaca do'a dan membaca satu surat pendek, kemudian mengkondisikan siswa untuk siap mengikuti 
pembelajaran dilanjutkan dengan memeriksa kehadiran, menjelaskan tujuan pembelajaran kemudian melakukan apersepsi dengan menanyakan materi yang dipelajari. Menurut Rusman (2017: 20-21) kegiatan pendahuluan dalam pembelajaran meliputi:

1. Menyiapkan peserta didik secara psikis dan fisik untuk mengikuti proses pembelajaran.

2. Mengajukan pertanyaan-pertanyaan tentang materi yang sudah dipelajari dan terkait dengan materi yang akan dipelajari.

3. Mengantarkan peserta didik kepada suatu permasalahan atau tugas yang akan dilakukan untuk mempelajari suatu materi dan menjelaskan tujuan pembelajaran atau KD yang akan dicapai.

4. Menyampaikan garis besar cakupan materi dan penjelasan tentang kegiatan yang akan dilakukan peserta didik untuk menyelesaikan permasalahan atau tugas.

Pada kegiatan inti, ketiga guru PAI menggunakan dua metode yang sama, yaitu metode ceramah dan metode tanya jawab untuk menceritakan atau menjelaskan materi pembelajaran. Namun menggunakan metode yang berbeda pula, yakni

1. Guru PAI kelas 2, menggunakan metode True or False. Sebelum pembelajaran, guru PAI terlebih dahulu menyiapkan media yang akan digunakan yaitu potongan kertas B dan S, kemudian media tersebut dibagikan kepada masing-masing siswa, dilanjutkan dengan guru PAI membacakan pertanyaan, dan siswa memilih jawaban dengan mengangkat kertas B atau S. Metode ini untuk melatih cara berpikir siswa dengan menjawab pertanyaan secara cepat dan tepat. Sebagaimana dijelaskan oleh Zaini, dkk (2008: 24) bahwa pembelajaran True or False (Benar atau salah) merupakan aktivitas kolaboratif yang dapat mengajak peserta didik untuk terlibat ke dalam materi dengan segera. Menurut Marjuki (2020: 218) Strategi true or false dapat mengembangkan sikap mandiri, cermat, selektif dan akurat.

2. Guru PAI kelas 3, menggunakan metode Role Play dengan metode simulasi, siswa menghafalkan teks drama selama lima menit kemudian siswa memerankan sebuah drama singkat secara perkelompok. Metode ini untuk mengembangkan kreativitas, imajinasi dan penghayatan siswa terhadap suatu peran. Dengan strategi Role Play ini dapat membuat siswa aktif dalam pembelajaran, Remiswal dan Rezki Amelia (2013: 46-48) mengatakan bahwa mereka secara aktif menggunakan otak, baik untuk menggunakan ide pokok, memecahkan masalah atau mengaplikasikan apa yang baru mereka pelajari dalam suatu persoalan yang ada dalam kehidupan nyata dan guru hanya berperan sebagai fasilitator Adapun kegiatan siswa pada strategi mengajar yang berpusat pada siswa yaitu: Bermain peran, menulis dengan kata-kata sendiri, belajar kelompok, memecahkan masalah, diskusi dan debat, mempraktikan keterampilan dan melakukan kegiatan penyelidikan

Pada pelaksanaan pembelajaran aktif, terdapat prinsip-prinsip yang ada dalam al-Qur'an, seperti prinsip partisipasi aktif. Pada prinsip ini dituntut bagi orang yang belajar agar ikut berpartisipasi aktif dalam pembelajaran. Hal tersebut sebagaimana yang tertulis dalam firman Allah surat Al-Maidah ayat 2 :

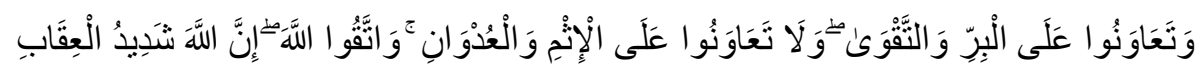

Artinya: “... Dan tolong-menolonglah kamu dalam (mengerjakan) kebajikan dan takwa, dan jangan tolong-menolong dalam berbuat dosa dan pelanggaran. Dan bertakwalah kamu kepada Allah, sesungguhnya Allah amat berat siksa-Nya." (Q.S. Al-Maidah: 2) Ayat tersebut menjelaskan tentang tolong menolong dalam segala hal. Begitu juga dengan proses pembelajaran aktif. Proses pembelajaran adalah suatu proses yang sangat membutuhkan perilaku tolong menolong, pembelajaran aktif membutuhkan adanya kerja sama antara beberapa komponen pembelajaran. Pada umumnya dalam pembelajaran aktif pendidik menggunakan model pembelajaran yang mengutamakan kerja sama, maka disini siswa dituntut untuk aktif dan saling bekerja sama dengan teman-temannya. Disamping itu pembelajaran aktif tidak akan berhasil jika tidak adanya kerja sama antara guru dan peserta didik. Jika tidak adanya kerja sama antara guru dan peserta didik maka adanya kesenjangan pemahaman tentang pembelajaran aktif yang mana pendidik 
bermalas-malasan, guru tidak tentu arah dalam melaksanakan dan merancang pembelajaran di kelas, sedangkan yang aktif justru siswanya, siswa diminta untuk mencatat, menulis, meringkas dan dibebani dengan tugas rumah yang banyak sekali.

Selain membuat siswa dapat berpikir secara aktif, strategi ini juga dapat meningkatkan inovatif siswa. Pembelajaran inovatif merupakan konsep belajar yang membantu guru mengaitkan antara materi yang diajarkan dengan situasi dunia nyata siswa dan mendorong siswa membuat hubungan antara pengetahuan yang dimilikinya dengan penerapannya dalam kehidupan mereka sebagai anggota keluarga dan masyarakat. Dengan konsep itu, hasil pembelajaran diharapkan lebih bermakna bagi siswa. Proses pembelajaran berlangsung alamiah dalam bentuk kegiatan siswa bekerja dan mengalami, bukan mentransfer pengetahuan dari guru ke siswa, strategi pembelajaran lebih dipentingkan daripada hasil. Untuk membantu siswa memahami konsep-konsep dan memudahkan guru dalam mengajarkan konsep-konsep tersebut diperlukan suatu pendekatan pembelajaran yang berlangsung mengaitkan materi konteks pelajaran dengan pengalaman nyata dalam kehidupan sehari-hari. Menurut Remiswal dan Rezki Amelia (2013: 60) kriteria inovatif meliputi adanya kegiatan-kegiatan baru, adanya ide-ide baru, menggunakan pendekatan, metode, dan media yang baru serta adanya modifikasi dalam proses pembelajaran.

3. Guru PAI kelas 6, menggunakan metode Reading Aloud dan Teks Acak dengan menggunakan metode drill, guru membacakan ayat sepenggal-sepenggal, kemudian siswa mengikutinya secara bergiliran agar siswa lebih mudah dalam menghafalnya. Dengan metode teks acak, siswa ditugaskan untuk menyusun ayat dan arti dari Q.S.AlMaidah ayat 2-3. Siswa sebagai penilaian dan melihat apakah siswa sudah benar-benar hafal atau belum, selain itu juga untuk memperkuat dan mengingatkan kembali hafalan siswa. Menurut Aswan (2016: 69) Teks acak termasuk strategi untuk mengingat kembali teks acak, strategi ini sangat baik digunakan untuk mata pelajaran yang menekankan kepada hafalan seperti Al-Qur'an dan Hadist.

Dengan menggunakan strategi Reading Aloud dan Teks Acak, tujuan pembelajaran telah tercapai dengan optimal, siswa dapat membaca, menghafal dan mememahami isi kandungan surat Al-Maidah: 2-3. Menurut Remiswal dan Rezky Amelia (2013: 98) bahwa pembelajaran dapat dikatakan efektif (effective) jika mencapai sasaran atau minimal mencapai kompetensi dasar yang telah ditetapkan. Di samping itu, yang juga penting adalah banyaknya pengalaman dan hal baru yang didapat siswa. Guru pun diharapkan memperoleh pengalaman baru sebagai hasil interaksi dua arah dengan siswanya. Atau bisa juga dikatakan secara harfiah efektif itu memiliki makna manjur, mujarab, berdampak, membawa pengaruh, memiliki akibat dan membawa hasil. Sedangkan pembelajaran yang efektif adalah pembelajaran yang menghasilkan apa yang harus dikuasai oleh siswa setelah proses pembelajaran berlangsung (seperti apa yang tertera pada tujuan pembelajaran).

Selain menjadikan pembelajaran menjadi efektif, siswa juga dapat berpartisipasi secara aktif dalam kegiatan pembelajaran, siswa berpikir dan berdiskusi bagaimana menyusun kata dengan baik dan benar. Kriteria pembelajaran aktif yaitu siswa melakukan sesuatu dan memikirkan apa yang mereka lakukan seperti: menulis, berdiskusi, berdebat, memecahkan masalah, mengajukan pertanyaan, menjawab pertanyaan, menjelaskan, menganalisis, mensintesa, dan mengevaluasi. (Remiswal dan Rezky Amelia, 2013: 60) Pada kegiatan akhir, yang dilakukan oleh ketiga guru PAI yaitu dengan mengapresiasi hasil yang telah dilakukan siswa selama berpartisipasi dalam pembelajaran, kemudian menyimpulkan dan menanyakan kembali materi yang telah dibahas, serta memberikan motivasi untuk siswa. Menurut Aswan (2016: 19) motivasi yaitu kecenderungan hati yang mendorong seseorang untuk melakukan suatu tindakan. Sedangkan menurut E. Mulyasa dkk (2016:174) motivasi merupakan salah satu faktor yang dapat meningkatkan kualitas pembelajaran, karena peserta didik akan belajar dengan sungguh-sungguh apabila memiliki motivasi yang tinggi. Maka seorang pendidik yang baik akan selalu memotivasi anak didiknya untuk belajar dan berkarya, pendidik yang seperti itu akan 
mengajak setiap anak didiknya untuk mengembangkan kreativitas dan keahliannya. Dari penjabaran tersebut, dapat diketahui bahwa pemberian motivasi oleh pendidik bisa jadi menjadi titik terang atau pelita bagi peserta didik dalam meningkatkan minat belajar siswa. Dan bisa jadi melalui motivasi tersebut peserta didik akan semangat berkreasi dan berkreativitas dalam kehidupan ini. . (Remiswal dan Rezky Amelia, 2013: 93)

\section{Evaluasi pembelajaran menggunakan model PAIKEM pada mata pelajaran Pendidikan Agama Islam di SDN X Astanaanyar}

Dalam melakukan penilaian, ketiga guru PAI menggunakan penilaian proses dan penilaian hasil belajar. Penilaian proses dilakukan ketika proses pembelajaran berlangsung, dengan mengamati siswa. Sedangkan penilaian hasil belajar dilakukan dengan tes tertulis dan test lisan atau praktek.

Untuk melakukan penilaian ketika proses pembelajaran berlangsung, ketiga guru PAI tidak hanya memberikan soal atau pertanyaan untuk dijawab, melainkan guru juga mengamati siswa ketika belajar untuk mencapai penilaian ranah afektif. Menurut Remiswal dan Rezky Amelia (2013: 93) penilaian berbasis PAIKEM dapat dilakukan bahwa penilaian tidak hanya dilakukan pada akhir dari proses pembelajaran saja, tetapi juga harus dilakukan pada awal pembelajaran, baik penilaian proses maupun penilaian hasil belajar.

Penilaian proses adalah penilaian yang dimaksudkan untuk mengetahui kualitas proses pembelajaran. Proses pembelajaran yang berkualitas jika berjalan lancar, efektif, elisien, dan termotivasinya SISwa dalam belajar. Penilaian proses dapat dilakukan dengan observasi atau menggunakan lembar pengamatan. Komponen yang dinilai seperti kreativitas, keaktifan. kerja sama, dan tanggung jawab.

Penilaian hasil belajar merupakan penilaian yang bertujuan untuk mengumpulkan informasi seberapa jauh pengetahuan dan kemampuan yang telah dikuasai oleh siswa setelah kegiatan pembelajaran. Pada saat kegiatan pembelajarun dapat dilakukan di awal kegiatan pembelajaran (pre test) dan di akhir kegiatan pembelajaran (post test). Pre test adalah pertanyaan di awal kegiatan pembelajaran mengenai bahan pelajaran yang akan disampaikan, untuk mengetahui tingkat pengetahuan dan kemampuan siswa sebelum menerima bahan pelajaran, dan post test adalah pertanyaan di akhir kegiatan pembelajaran untuk mengetahui tingkat pengetahuan dan kemampuan siswa setelah menerima bahan pelajaran tersebut. Alat tes yang digunakan tertulis, lisan atau tindakan. (Aswan, 2016: 41)

Dalam menyusun soal tertulis, guru PAI membuat soal dengan indikator soal HOTS (Higher Order Thinking Skills). Menurut (2019: 39) Soal-soal HOTS sangat direkomendasikan untuk digunakan pada berbagai bentuk penilaian kelas dan Ujian Sekolah. Untuk menginspirasi guru menyusun soal-soal HOTS di tingkat satuan pendidikan, yaitu dengan karakteristik soalsoal HOTS yakni mengukur kemampuan berpikir tingkat tinggi, bersifat divergen, menggunakan multirepresentasi, berbasis permasalahan kontekstual dan menggunakan bentuk soal beragam.

\section{Kesimpulan}

Berdasarkan pembahasan dalam penelitian ini, peneliti menyimpulkan beberapa hasil penelitian sebagai berikut:

1. Perencanaan pembelajaran menggunakan model PAIKEM pada mata pelajaran Pendidikan Agama Islam di SDN X Astanaanyar sesuai dengan karakteristik PAIKEM, yakni guru PAI menentukan materi dan tujuan pembelajaran, metode dan media yang bervariasi, langkah-langkah pembelajaran yang efektif dan mencari sumber belajar dari berbagai aspek.

2. Pelaksanaan pembelajaran menggunakan model PAIKEM pada mata pelajaran Pendidikan Agama Islam di SDN X Astanaanyar membuat siswa belajar secara aktif, inovatif dan efektif dengan menggunakan berbagai metode, yakni metode ceramah dan metode tanya jawab yang disertai dengan metode True or False, Role Play dengan metode simulasi, Reading Aloud dengan metode drill dan Teks Acak.

3. Evaluasi pembelajaran menggunakan model PAIKEM pada mata pelajaran Pendidikan Agama Islam di SDN X Astanaanyar sesuai dengan penilaian berbasis PAIKEM, yaitu 
dengan penilaian proses yang mengamati siswa ketika proses pembelajaran berlangsung. dan penilaian hasil belajar dengan tes tulis maupun tes lisan.

\section{Acknowledge}

Terimakasih kepada Orangtua yang selalu mendo'akan dan memotivasi, serta kepada Dosen Pembimbing yang telah sabar dan memberikan ilmunya

\section{Daftar Pustaka}

[1] Asfiati, 2020. Visualisasi dan Virtualisasi Pembelajaran Pendidikan Agama Islam Versi Program Merdeka Belajar dalam Tiga Era. 1 ed. Jakarta: Kencana.

[2] Aswan, 2016. Strategi Pembelajaran Berbasis PAIKEM. Revisi ed. Yogyakarta: Aswaja Pressindo.

[3] Ayuhana, M. M., 2015. Perkembangan Kurikulum Pendidikan Agama Islam Sekolah Dasar di Indonesia. Tarbawi, Volume 12, pp. 170-184.

[4] B.Uno, H. \& Mohammad, N., 2015. Belajar dengan Pendekatan PAILKEM. 6 ed. Jakarta: Bumi Aksara.

[5] Marjuki, 2020. 181 Model PAIKEM Berbasis Pendekatan Saintifik. 1 ed. Bandung: PT Remaja Rosdakarya.

[6] Mulyasa, E., Iskandar, D. \& Aryani, W. D., 2016. Revolusi dan Inovasi Pembelajaran. 1 ed. Bandung: PT Remaja Rosdakarya.

[7] R. \& Amelia, R., 2013. Format Pengembangan Strategi PAIKEM Dalam Pembelajaran Agama Islam. 1 ed. Yogyakarta: Graha Ilmu.

[8] Setiawan, W. et al., 2019. Buku Penilaian Berorientasi Higher Order Thinking Skills. Jakarta: Direktorat Jenderal Guru dan Tenaga Kependidikan Kementerian Pendidikan dan Kebudayaan. 